\title{
Effects of background mutations and single nucleotide polymorphisms (SNPs) on the Disc1 L100P behavioral phenotype associated with schizophrenia in mice
}

Yosefu Arime', Ryutaro Fukumura ${ }^{2}$, Ikuo Miura ${ }^{3}$, Kazuyuki Mekada ${ }^{4}$, Atsushi Yoshiki ${ }^{4}$, Shigeharu Wakana ${ }^{3}$, Yoichi Gondo ${ }^{2}$ and Kazufumi Akiyama ${ }^{1^{*}}$

\begin{abstract}
Background: Disrupted-in-schizophrenia 1 (DISC1) is a promising candidate susceptibility gene for psychiatric disorders, including schizophrenia, bipolar disorder and major depression. Several previous studies reported that mice with N-ethyl-N-nitrosourea (ENU)-induced L100P mutation in Disc1 showed some schizophrenia-related behavioral phenotypes. This line originally carried several thousands of ENU-induced point mutations in the C57BL/6 J strain and single nucleotide polymorphisms (SNPS) from the DBA/2 J inbred strain.

Methods: To investigate the effect of Disc1 L100P, background mutations and SNPs on phenotypic characterization, we performed behavioral analyses to better understand phenotypes of Disc1 L100P mice and comprehensive genetic analyses using whole-exome resequencing and SNP panels to map ENU-induced mutations and strain-specific SNPS, respectively.

Results: We found no differences in spontaneous or methamphetamine-induced locomotor activity, sociability or social novelty preference among Disc1 L100P/L100P, L100P/+ mutants and wild-type littermates. Whole-exome resequencing of the original G1 mouse identified 117 ENU-induced variants, including Disc1 L100P per se. Two females and three males from the congenic L100P strain after backcrossing to C57BL/6 J were deposited to RIKEN BioResource Center in 2008. We genotyped them with DBA/2 J × C57BL/6 J SNPs and found a number of the checked SNPs still remained.
\end{abstract}

Conclusion: These results suggest that causal attribution of the discrepancy in behavioral phenotypes to the Disc1 L100P mutant mouse line existing among different research groups needs to be cautiously investigated in further study by taking into account the effect(s) of other ENU-induced mutations and/or SNPs from DBA/2 J.

Keywords: Disrupted-in-schizophrenia 1 (DISC1), ENU mutagenesis, Locomotor activity, Methamphetamine, Social interaction, Whole-exome resequencing, Strain-specific SNPS

\footnotetext{
* Correspondence: kazufuak@dokkyomed.ac.jp

'Department of Biological Psychiatry and Neuroscience, Dokkyo Medical

University School of Medicine, 800 Kitakobayashi, Mibu-machi, Shimotsuga-gun,

Tochigi 321-0293, Japan

Full list of author information is available at the end of the article
} 


\section{Background}

Schizophrenia is a devastating mental disorder with a significant genetic component that affects approximately $0.5-1.0 \%$ of the general population. Based on genetic epidemiological studies, it was estimated that schizophrenia has a heritability of $60-80 \%$ [1,2]. Disruptedin-schizophrenia 1 (DISC1) is one of the candidate susceptibility genes for a spectrum of major psychiatric disorders. DISC1 was originally identified on chromosome 1 by analyzing a large Scottish pedigree showing a heavy burden of major psychiatric disorders associated with balanced chromosomal translocation (1:11)(q42.1:q14.3) $[3,4]$. DISC1 is implicated in the genetic risk for many aspects of quantitative cognitive traits of psychotic patients [5-8]. Accumulating evidence indicates that DISC1 acts as a scaffold protein that in concert with numerous interacting proteins regulates neurogenesis, neuronal migration, neurite outgrowth, and signal transduction [9-11].

Mouse models for the genetic mutation of Disc1 are of relevance for unraveling the impact of gene disruption on neural integrity associated with schizophrenia. A number of conditional transgenic mouse models overexpressing truncated versions of human DISC1 protein under various exogenous promoters have been reported. In these models, truncated versions of human DISC1 protein are overexpressed either constitutively [12-14] or transiently during early postnatal life [15-18]. A mouse strain carrying a truncating lesion (25-bp deletion in exon 6) in the endogenous Disc1 orthologue has also been reported [19-21]. Although these mouse models display a range of psychiatric disease-related behavioral phenotypes, many have been inconsistent across studies due to differences in behavior tests and experimental design and the specific genetic aberrations.

An alternative method for generation of a mouse Disc1 model is to screen an archive of G1 mice carrying many $N$-ethyl- $N$-nitrosourea (ENU)-induced mutations. With this approach, it is feasible to identify an allelic series of ENU-induced mutations in a particular gene, in this case Disc1, as a gene-driven approach based on a priori assumptions of the function of a gene of interest $[22,23]$. Genomic DNA libraries from thousands of G1 mice born to ENU-mutagenized C57BL/6 J male mice were screened for a point mutation in Disc1, one of which was subsequently identified as conferring a L100P amino acid substitution in exon 2 [24]. Roder and his collaborators reported that the Disc1 L100P mouse line showed schizophrenia-like behavior, such as increased basal and amphetamine-induced open field activity, and deficits in prepulse inhibition (PPI) [24,25]. However, other independent research groups observed neither an increase in basal locomotor activity nor abnormal PPI [26,27].

Because ENU generates multitude, randomly distributed, single-base point mutations throughout the entire mouse genome, ENU mutant mouse lines may harbor unknown functional mutations other than those are assumed to contribute to the phenovariance of interest [22,23,28,29]. Additionally, ENU-mutagenized C57BL/6 J male mice at RIKEN were out-crossed to untreated DBA/2 J female mice to produce the original progeny (G1). Although heterozygous mice resulting from repeated backcrossing to the C57BL/6 J background were finally intercrossed to generate L100P/L100P homozygous mice, remaining ENU-induced mutations outside Disc1 and/or single nucleotide polymorphisms (SNPs) from DBA/2 J background may confound the causal relationship between L100P mutation and the behavioral phenotype. Disclosure of this information would provide a justification for the usage of ENU-mutagenesis to fully explain the phenotypic manifestation of the main causative mutation. Herein, we performed three experiments to better understand behavioral phenotypes of Disc1 L100P mice with reference to our new genetic data. First, we investigated the genetic background of the L100P strain that was reversely-deposited back to the Experimental Animal Division (EAD), RIKEN BioResource Center (BRC) by Roder's group [24]. The genetic background of the deposited L100P/L100P homozygous pairs and their offspring born via intercrossing between the homozygotes were investigated. Second, L100P/L100P, L100P/+ and wild-type littermates $(+/+)$, which were derived from the deposited L100P/L100P homozygous mice mated with the C57BL/6 J mice (details in Materials and Methods), were examined for schizophrenia-related behavioral phenotypes using open field and social interaction tests. Third, we conducted whole-exome resequencing analysis of the original G1 genome to screen for ENU-induced mutations in addition to the Disc1 L100P mutation. The results obtained were discussed in light of the validity and issue of Disc1 L100P mutant model.

\section{Methods}

\section{Animals}

Male and female homozygous Disc1 L100P/L100P mutant mice backcrossed to C57BL/6 J were deposited at the EAD at RIKEN BRC (Tsukuba, Japan, http://www.brc. riken.jp/lab/animal/en/) by another research group [24], and their offspring was bred to maintain the homozygosity (L100P/L100P). These L100P/L100P mutant male mice (Disc1 < Rgsc1390>) were obtained from RIKEN and then backcrossed to an inbred C57BL/6 J female (Japan Clea Co., Tokyo Japan) for one generation. The resultant $\mathrm{L} 100 \mathrm{P} /+$ progeny were intercrossed to generate L100P/ L100P, L100P/+ and +/+ littermates. Mice were weaned at postnatal day $25-28$ and segregated by sex; were housed $2-4$ per cage in a temperature-controlled $\left(25 \pm 1^{\circ} \mathrm{C}\right)$ and light-controlled room (light on 0600-1800 h) in plastic cages with ad libitum access to food and water. 
PCR-based genotyping was conducted with a primer pair (common forward primer: 5'-CCTGTCCCAAGG ACTGGCATC-3'; reverse primer for L100L wild-type: 5'-CAGGGACAAGGGAGCTCTTCA-3'; reverse primer for L100P mutants: 5'- CAGGGACAAGGGAGCTCT TCG-3') and genomic DNA extracted from tail biopsies using Hot Sodium Hydroxide and Tris (HotSHOT) method [30]. Age-matched male L100P/L100P, L100P/+ and $+/+$ mice (12-16 weeks old) were compared in behavioral analyses. To compare wild-type littermates with inbred C57BL/6 J mice, 12-16-week-old male C57BL/6 J mice were purchased from Japan Clea Co. (Tokyo, Japan). All experiments were performed in accordance with the Guidelines for Care and Use of Laboratory Animals, Dokkyo University School of Medicine and conformed to all Japanese federal rules and guidelines.

\section{Drug treatment}

Methamphetamine hydrochloride (Dainippon Pharmaceutical Co., Osaka, Japan) was dissolved in saline and administered subcutaneously (s.c.) in a volume of $10 \mathrm{ml} / \mathrm{kg}$.

\section{Behavioral analysis}

All behavioral analyses were recorded with a CCD camera and analyzed using video tracking software (ANY-maze ver. 4.82; Stoelting Co., USA). The apparatus was illuminated at approximately 300 lux. Mice were transferred to the experimental site at least $30 \mathrm{~min}$ before testing.

\section{Spontaneous locomotor activity}

Mice were placed individually in grey plastic cages $(42 \times 42 \times 30 \mathrm{~cm})$. Spontaneous locomotor activity was recorded in 5-min sessions during a 90-min test period, with distance traveled as the primary outcome measure.

\section{Methamphetamine-induced locomotor activity}

Mice were placed individually in grey plastic cages $(42 \times 42 \times 30 \mathrm{~cm})$ for a 30 -min habituation session and then injected subcutaneously with methamphetamine $(0.2,0.5$ or $1.0 \mathrm{mg} / \mathrm{kg})$ or saline. Locomotor activity was recorded continuously during the 30-min habituation period and for $60 \mathrm{~min}$ after injection of saline or methamphetamine. To verify effects of genetic characteristics on behavioral phenotypes, methamphetamine-induced locomotor activity was compared among mice in the following experiments. In experiment 1, effects of L100P on methamphetamine-induced locomotor activity were compared in age-matched male littermates (L100P/L100P, L100P/+ and +/+). In experiment 2, effects of genetic background on methamphetamine-induced locomotor activity were tested by comparing inbred C57BL/6 J mice with the results of wild-type littermate born to Disc1 L100P mutant line obtained from the experiment 1 .

\section{Sociability and social novelty preference tests}

Effects of the L100P point mutation on social behavior were assessed according to previously described methods $[24,31]$ with minor modifications. A three-chamber apparatus was constructed of clear acrylic sheets; each chamber had a size of $19 \times 40 \times 25 \mathrm{~cm}$ (width $\times$ depth $\times$ height). Each side chamber contained a wire-bar cup (Galaxy Cup, Spectrum Diversified Designs, Inc., $\mathrm{OH}$, USA) placed on either side of the arena. Two dividing walls containing doors allowed access to each of the side chambers from the center chamber. The behavioral test consisted of three sessions: (1) habituation, (2) sociability and (3) social novelty preference. In the habituation session (1), the subject mouse was placed in the center chamber and allowed to freely explore all three chambers for $10 \mathrm{~min}$. In the sociability session (2), following the habituation session, the subject mouse was introduced in the center chamber for $1 \mathrm{~min}$ with access to the side chambers blocked by white partitions. An unfamiliar male C57BL/6 J mouse (Stranger 1) was enclosed in the wire-bar cup in one of the side chambers. The location of Stranger 1 alternated among subject mice. On removal of partitions, the subject mouse was allowed to freely explore the entire apparatus for $10 \mathrm{~min}$. Time spent within the interaction zone (an oblong area of $19 \times 15 \mathrm{~cm}$ containing the wire-bar cup) and the number of entries into each chamber was measured. In the social novelty preference test (3) conducted after the sociability test, the subject mouse was placed in the center chamber for 1 min. An unfamiliar intruder male C57BL/6 J mouse (Stranger 2) was enclosed in the wire-bar cup in the other side chamber. Time spent in the interaction zones and the number of entries into each chamber was measured.

\section{SNP-typing for genetic background of L100P/L100P mutant mice}

We genotyped 117 SNPs, which were openly available in the SNP database of RIKEN BRC (http://ja.brc.riken.jp/ lab/jmc/mapping.html), distributed at approximately 15 -cM intervals over the entire mouse genome in 8 mice; 3 males and 1 female of the L100P/L100P deposited mice to the RIKEN EAD and 1 male and 3 female progeny from the deposited pairs to distinguish between C57BL/ $6 \mathrm{~J}$ and DBA/2 J genetic backgrounds.

\section{Exome re-sequencing of the original G1 carrying the L100P mutation}

We used the SureSelect Mouse All Exon Kit (Agilent, Santa Clara, CA, USA) to enrich whole exons from genomic DNA of the G1 mouse. We performed resequencing using SOLiD4 (Life Technologies, Carlsbad, CA, USA) as reported previously [32]. 


\section{Statistical analysis}

Statistical analysis was conducted using SPSS software (ver. 19, IBM Japan). Data were analyzed using paired t-tests, one-way ANOVA, two-way ANOVA or twoway repeated measures ANOVA as appropriate. The Greenhouse-Geisser correction for repeated measures was applied as necessary.

\section{Results}

\section{Spontaneous locomotor activity}

Spontaneous locomotor activity in the open field declined to a similar extent in all three genotypes (L100P/L100P, $\mathrm{L} 100 \mathrm{P} /+$ and $+/+$ ) over $90 \mathrm{~min}$ (Figure 1A). Two-way repeated measures ANOVA revealed no significant genotype $\times$ time interaction $(F(20.169,554.636)=0.884$, $p=0.609)$. Moreover, total distance traveled was similar among genotypes (Figure 1B). ANOVA revealed no main effect of genotype on total distance traveled $(\mathrm{F}(2,55)=$ $0.785, p=0.461)$.

\section{Methamphetamine-induced locomotor activity}

There was no difference among genotypes in locomotor activity during either the habituation period or postinjection period (Figure 2A-D). ANOVA indicated no significant genotype $\times$ drug interaction on total distance traveled $(\mathrm{F}(6,117)=0.214, p=0.972)$, no main effect of drug treatment $(\mathrm{F}(3,117=1.824, p=0.147)$ and no main effect of genotype $(\mathrm{F}(2,117)=0.098, p=0.907)$ during 30-min habituation (Figure 2E). Similarly, there was no significant genotype $\times$ drug interaction on total distance traveled among groups $(F(6,117)=0.433$, $p=0.856)$ or a main effect of genotype $(\mathrm{F}(2,117)=0.015$, $p=0.985$ ) during $60 \mathrm{~min}$ after drug injection (Figure 2F). Methamphetamine $(0.5$ and $1.0 \mathrm{mg} / \mathrm{kg})$ significantly increased total distance traveled in all genotypes. ANOVA revealed a significant effect of drug treatment
$(\mathrm{F}(3,117)=19.844, p<0.001)$; Tukey post hoc analysis showed a significant effect of $0.5 \mathrm{mg} / \mathrm{kg}(p<0.01)$ and $1.0 \mathrm{mg} / \mathrm{kg}(p<0.001)$ methamphetamine versus saline.

To test for effects of putatively existing genetic elements inherited from the DBA/2 J background on spontaneous and methamphetamine-induced locomotion, we compared wild-type progeny born to Disc1 L100P/+ mutants and inbred C57BL/6 J mice. There was no difference in either spontaneous or methamphetamine-induced locomotor activity (Figure 2G-H). ANOVA revealed no significant drug $\times$ genetic background interaction in either the 30-min habituation period $(\mathrm{F}(3,59)=0.779, p=0.511)$ or the 60-min post-injection period $(\mathrm{F}(3,59)=0.198$, $p=0.898)$. There was no main effect of genetic background on locomotor activity in either the habituation period $(\mathrm{F}(1,59)=0.806, p=0.373)$ or the post-injection period $(F(1,59)=0.195, p=0.660)$. There was no main effect of drug treatment on total distance traveled during the habituation period $(\mathrm{F}(3,59)=0.244, p=0.866)$ (Figure 2G). Methamphetamine $(0.5$ and $1.0 \mathrm{mg} / \mathrm{kg})$ significantly increased locomotor activity in both wild-type progeny of Disc1 L100P/+ mice and inbred C57BL/6 J mice (Figure $2 \mathrm{H}$ ). There was a significant main effect of drug treatment on total distance traveled after the drug administration $(\mathrm{F}(3,59)=12.114, \mathrm{p}<0.001)$ and significant effects of both methamphetamine $0.5 \mathrm{mg} / \mathrm{kg}(\mathrm{p}<0.01)$ and $1.0 \mathrm{mg} / \mathrm{kg}(\mathrm{p}<0.001)$ versus saline as revealed by Dunnett's T3 post hoc analysis.

\section{Sociability and social preference test}

In the sociability session, two-way ANOVA revealed a significant interaction between genotype and the chambers in time spent in the interaction zones $(\mathrm{F}(2,50=3.495$, $p<0.05)$. Post hoc analyses revealed no significant main effect of genotype for either side, but did show a significant main effect of preference for the stranger
A

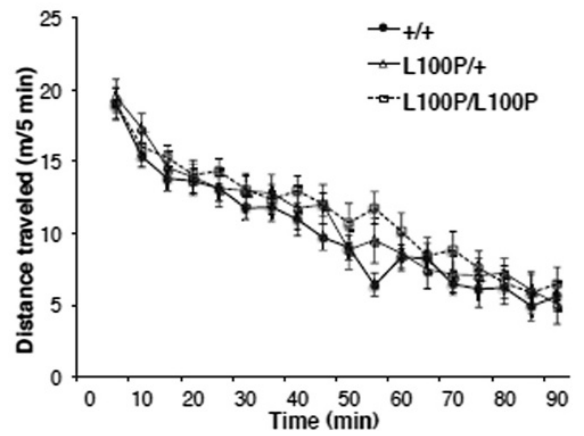

B

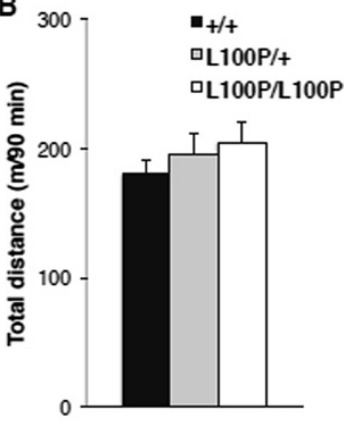

Figure 1 Comparison of spontaneous locomotor activity in the open field. (A) Distance traveled in 5 min bins during spontaneous locomotion by Disc1 L100P/L100P mutants $(n=20)$, L100P/+ mutants $(n=18)$, and wild-type $(+/+)$ littermates $(n=20)$. Repeated measures ANOVA revealed no significant genotype $\times$ time interaction. Data are expressed as mean \pm SEM. (B) Total distance traveled over 90 min. ANOVA revealed no significant main effect of genotype. Data are expressed as mean \pm SEM. 

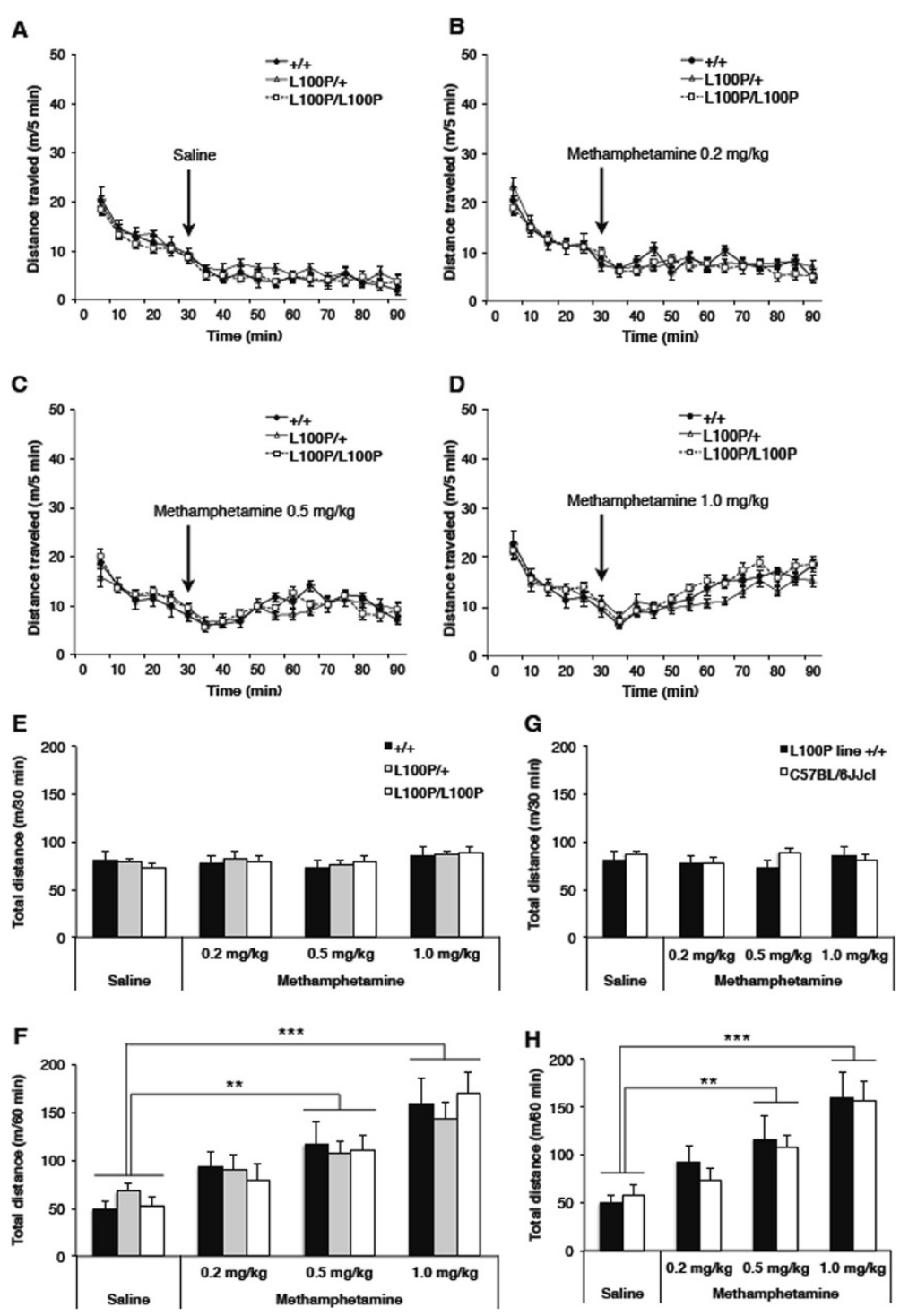

Figure 2 Effect of methamphetamine on locomotor activity in the open field. (A-D) Distance traveled in 5 min bins following methamphetamine or saline treatment. Repeated measures ANOVA revealed no significant genotype $\times$ time interactions among Disc1 L100P/L100P $(n=11-12), L 100 P /+(n=11-13)$, and $+/+$ littermates $(n=8-9)$. Data are expressed as mean \pm SEM. (E) Total distance traveled during 30 min before drug injection. ANOVA revealed no significant genotype $\times$ drug interaction or a main effect of genotype. (F) Total distance traveled during 60 min after drug injection. ANOVA revealed a significant main effect of the drug. Methamphetamine elicited hyperlocomotion in a dose-dependent manner in all three genotypes. $(\mathbf{G}, \mathbf{H})$ Effect of methamphetamine on the locomotor activity of inbred C57BL/6 J mice and +/+ littermates derived from Disc1 L100P mutant line in the open field. (G) Total distance traveled for 30 min before drug injection. ANOVA revealed no significant genetic background $\times$ drug interaction or a main effect of genetic background. (H) Total distance traveled over 60 min after drug injection. ANOVA revealed a significant main effect of drug. Methamphetamine elicited hyperlocomotion in a dose-dependent manner in both two groups. L100P line $+/+$ in $(\mathbf{G}, \mathbf{H})$ and $+/+$ in $(\mathbf{E}, \mathbf{F})$ were the same mice for each treatment group. Data are expressed as mean \pm SEM. ${ }^{* *} p<0.01$ or ${ }^{* *} p<0.001$ compared with the saline-treated group.

mouse (Stranger 1) for all genotypes $(+/+: p<0.01$, L100P/+: $p<0.001$, L100P/L100P: $p<0.05)$ on stay duration (Figure 3A). Two-way repeated measures ANOVA showed neither a significant genotype $\times$ chamber interaction for the number of entries nor a main effect of genotype, but did show a significant main effect of the chamber $(\mathrm{F}(1.533,76.638)=403.012, p<0.001)$. Post hoc analyses revealed a significant main effect of preference for the center zone for the combined group (Empty: $p<0.001$, Stranger 1: $p<0.001$ ), but the number of transitions into the chamber containing Stranger 1 did not differ from the number of transitions into the empty chamber. In the social novelty preference session, two-way repeated measures ANOVA showed neither a significant genotype $\times$ side interaction in time spent in the interaction zones nor a significant main effect of genotype, but did reveal a 


\section{A}

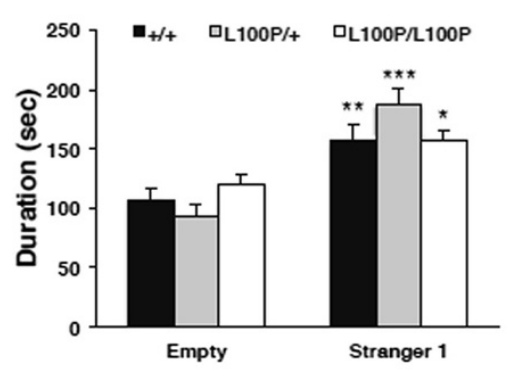

Sociability

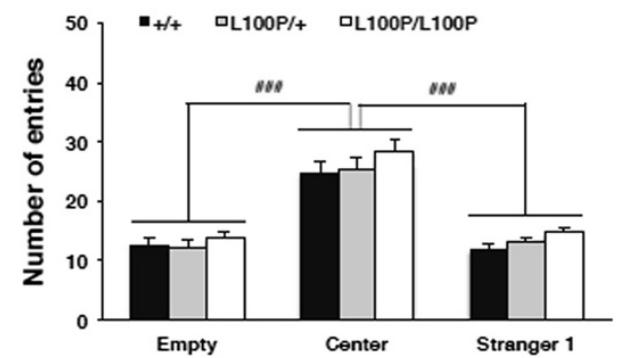

B

Social novelty preference
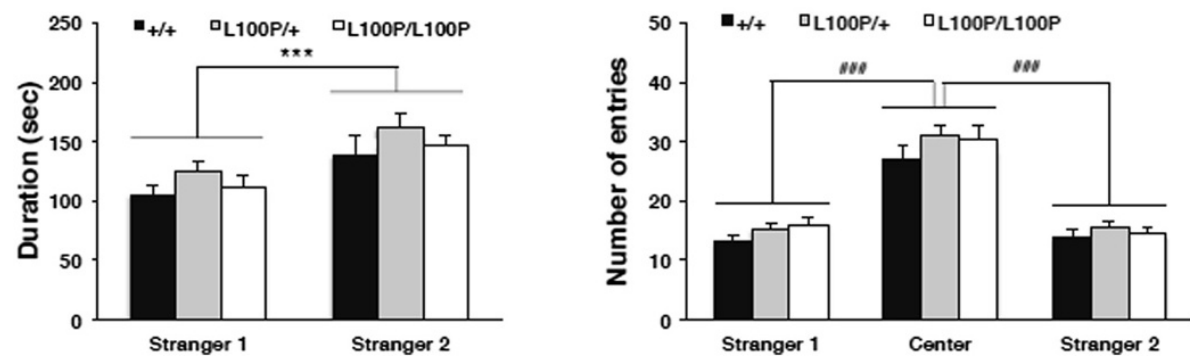

Figure 3 Comparison of sociability and social novelty preference among Disc1 L100P/L100P, L100P/+, and +/+ littermates. (A) Sociability: mean time spent near the empty cage (Empty) or the cage containing the unfamiliar mouse (Stranger 1) (left), and the number of entries into each chamber (right). (B) Mean time spent near the cage containing the first unfamiliar mouse (Stranger 1) or a new unfamiliar mouse (Stranger 2) (left), and the number of entries into each chamber (right). All values are expressed as mean \pm SEM for each group. ${ }^{*} p<0.05$, ${ }^{* *} p<0.01$ or ${ }^{* * *} p<0.001$ versus time spent near the unfamiliar mouse (Stranger 1). ${ }^{\# \#} p<0.001$ versus the number of entries into the center chamber.

significant main effect of both sides $(\mathrm{F}(1,50)=17.247$, $p<0.001)$. Post hoc analyses revealed a significant main effect of preference for the unfamiliar intruder (Stranger 2) compared with the by-then familiar mouse (Stranger 1$)$ for the combined group $(p<0.001)$ (Figure 3B). Two-way repeated measures ANOVA showed neither a significant genotype $\times$ chamber interaction for the number of entries nor a significant main effect of genotype, but did show a significant main effect of the chamber ( $F(1.669$, $83.456)=346.789, p<0.001)$. Post hoc analyses revealed a significant main effect of preference for the center zone for the combined group (Stranger 1: $p<0.001$, Stranger 2: $p<0.001$ ), but the number of transitions into the chamber containing Stranger 1 did not differ from the number of transitions into the chamber containing Stranger 2.

\section{SNP typing for genetic background of L100P/L100P mutant mouse line (Disc1 < Rgsc1390>)}

Despite backcrosses, all the genotyped eight L100P/ L100P homozygotes harbored DBA/2 J-derived SNP alleles, which were either homozygous or heterozygous variant (Additional file 1: Figure S1). Genome-wide SNP panel analysis revealed that the numbers of SNPs indicative of homozygosity or heterozygosity for DBA/2 J ancestry varied among individual mice. Each mouse harbored 1-5 homozygous and 8-12 heterozygous loci for DBA/2 J-derived SNP alleles (Additional file 2: Table S1).

\section{Exome resequencing of the original G1 genome carrying L100P mutation}

There was no single nucleotide mutation in the Disc1 exons other than L100P. In addition to the L100P mutation, exome resequencing analysis revealed 117 single nucleotide mutations in the exome and exome-flanking regions of the genomic DNA from the original G1 mouse, the F1 progenitor born to an ENU-treated G0 mouse (Table 1). Disc1 L100P and two other mutations (in Rab11fip1, known as Rab-coupling protein and $N r 3 c 2$ ) were found in chromosome 8. Other variants included synonymous coding variants (5), nonsynonymous coding (27 including ryr3, encoding the intracellular $\mathrm{Ca} 2+$ release channel ryanodine receptor 3 and Rab11fip1), knockout-equivalent nonsense (Als2 and Ttll1), essential splice site variants (3), 5' UTR (3, including $D y x 1 c 1$, a susceptibility gene for dyslexia), 3' UTR (9), and intronic mutations (49). Base substitution spectra of the 117 ENU-induced mutations were $\mathrm{A} / \mathrm{T}$ to $\mathrm{T} / \mathrm{A}$ transversions (26.5\%), $\mathrm{A} / \mathrm{T}$ to $\mathrm{G} / \mathrm{C}$ transitions (39.3\%), $\mathrm{G} / \mathrm{C}$ to $\mathrm{A} / \mathrm{T}$ transitions (18.8\%), $\mathrm{A} / \mathrm{T}$ to $\mathrm{C} / \mathrm{G}$ transversions $(6.8 \%)$, and $\mathrm{G} / \mathrm{C}$ to $\mathrm{T} / \mathrm{A}$ transversions $(8.5 \%)$. 
Table 1 List of ENU-induced mutations in G1 mouse of Disc1<Rgsc1390>

\begin{tabular}{|c|c|c|c|c|c|c|c|}
\hline Gene symbol & Entrez Gene ID & Chromosome & $\begin{array}{l}\text { Position } \\
\text { (MM9) }\end{array}$ & $\begin{array}{c}\text { Base } \\
\text { change }\end{array}$ & Spectrum & Classification & Amino acid substitution \\
\hline Pkhd1 & 241035 & 1 & $20,530,613$ & $\mathrm{~T} \rightarrow \mathrm{A}$ & AT to TA transversions & Intronic & \\
\hline Trak2 & 70827 & 1 & $58,975,614$ & $A \rightarrow G$ & AT to $\mathrm{GC}$ transitions & Essential splice site & \\
\hline Als2 & 74018 & 1 & $59,235,933$ & $A \rightarrow T$ & AT to TA transversions & Stop gained & $Y->X$ \\
\hline Ngef & 53972 & 1 & $89,379,202$ & $A \rightarrow T$ & AT to TA transversions & Nonsysnonymous & $\mathrm{I}->\mathrm{N}$ \\
\hline $2310035 C 23 R i k$ & 227446 & 1 & $107,592,127$ & $A \rightarrow G$ & AT to $\mathrm{GC}$ transitions & Intronic & \\
\hline Ikbke & 56489 & 1 & $133,172,385$ & $\mathrm{C} \rightarrow \mathrm{A}$ & GC to TA transversions & Nonsysnonymous & $A->S$ \\
\hline$C d c 73$ & 214498 & 1 & $145,542,523$ & $A \rightarrow T$ & AT to TA transversions & Nonsysnonymous & $\mathrm{S}->\mathrm{T}$ \\
\hline Nmnat2 & 226518 & 1 & $154,936,083$ & $A \rightarrow T$ & AT to TA transversions & Intronic & \\
\hline Atf6 & 226641 & 1 & $172,724,783$ & $\mathrm{G} \rightarrow \mathrm{A}$ & GC to AT transitions & Intronic & \\
\hline Gm5706 & 435657 & 1 & $184,322,753$ & $A \rightarrow G$ & AT to GC transitions & Genic & \\
\hline lars2 & 381314 & 1 & $187,127,260$ & $A \rightarrow T$ & AT to TA transversions & Nonsysnonymous & $\mathrm{I}->\mathrm{N}$ \\
\hline Dhtkd1 & 209692 & 2 & $5,831,429$ & $A \rightarrow G$ & AT to $\mathrm{GC}$ transitions & Synonymous & \\
\hline Cacna1b & 12287 & 2 & $24,506,396$ & $A \rightarrow G$ & AT to GC transitions & Intronic & \\
\hline Dolk & 227697 & 2 & $30,140,520$ & $A \rightarrow G$ & AT to $\mathrm{GC}$ transitions & Synonymous & \\
\hline Lrp1b & 94217 & 2 & $40,854,333$ & $A \rightarrow C$ & AT to $C G$ transversions & Intronic & \\
\hline $\mathrm{Neb}$ & 17996 & 2 & $52,114,402$ & $C \rightarrow A$ & GC to TA transversions & Nonsysnonymous & $R->L$ \\
\hline Gm13559 & 674940 & 2 & $58,593,845$ & $A \rightarrow G$ & AT to $\mathrm{GC}$ transitions & Genic & \\
\hline Ttn & 22138 & 2 & $76,553,805$ & $\mathrm{C} \rightarrow \mathrm{T}$ & GC to AT transitions & Nonsysnonymous & $M->1$ \\
\hline Olfr1270 & 258987 & 2 & $89,989,253$ & $\mathrm{~T} \rightarrow \mathrm{C}$ & AT to GC transitions & Synonymous & \\
\hline Ext2 & 14043 & 2 & $93,558,064$ & $\mathrm{C} \rightarrow \mathrm{T}$ & GC to AT transitions & Intronic & \\
\hline Ryr3 & 20192 & 2 & $112,701,983$ & $\mathrm{C} \rightarrow \mathrm{A}$ & GC to TA transversions & Nonsysnonymous & $G->W$ \\
\hline Fmn 1 & 14260 & 2 & $113,528,228$ & $\mathrm{~T} \rightarrow \mathrm{A}$ & AT to TA transversions & Intronic & \\
\hline Sel112 & 228684 & 2 & $140,071,126$ & $\mathrm{C} \rightarrow \mathrm{T}$ & GC to AT transitions & Nonsysnonymous & $A->T$ \\
\hline Setd7 & 73251 & 3 & $51,334,212$ & $\mathrm{~T} \rightarrow \mathrm{C}$ & AT to GC transitions & Intronic & \\
\hline Ift80 & 68259 & 3 & $68,794,587$ & $A \rightarrow T$ & AT to TA transversions & Intronic & \\
\hline \multirow[t]{2}{*}{ Asb17 } & 66772 & 3 & $153,516,522$ & $\mathrm{G} \rightarrow \mathrm{A}$ & GC to AT transitions & 3' UTR & \\
\hline & & 4 & $8,394,708$ & $\mathrm{~T} \rightarrow \mathrm{C}$ & AT to GC transitions & Intergenic & \\
\hline Esrp1 & 207920 & 4 & $11,277,315$ & $\mathrm{G} \rightarrow \mathrm{T}$ & GC to TA transversions & Intronic & \\
\hline Gm136 & 214568 & 4 & $34,699,557$ & $\mathrm{C} \rightarrow \mathrm{T}$ & GC to AT transitions & Nonsysnonymous & $A->T$ \\
\hline$N f \times 1$ & 74164 & 4 & $40,952,108$ & $\mathrm{~T} \rightarrow \mathrm{A}$ & AT to TA transversions & Intronic & \\
\hline Gm12608 & 664785 & 4 & $89,109,036$ & $\mathrm{~T} \rightarrow \mathrm{A}$ & AT to TA transversions & Genic & \\
\hline Tek & 21687 & 4 & $94,516,374$ & $\mathrm{~T} \rightarrow \mathrm{A}$ & AT to TA transversions & Nonsysnonymous & $S->T$ \\
\hline Dnajc6 & 72685 & 4 & $101,279,103$ & $C \rightarrow T$ & GC to AT transitions & Intronic & \\
\hline Txndc12 & 66073 & 4 & $108,533,802$ & $\mathrm{~T} \rightarrow \mathrm{A}$ & AT to TA transversions & Intronic & \\
\hline Gm12901 & 194197 & 4 & $122,935,965$ & $\mathrm{~T} \rightarrow \mathrm{C}$ & AT to GC transitions & Genic & \\
\hline Tmprss11e & 243084 & 5 & $87,156,236$ & $C \rightarrow T$ & GC to AT transitions & Intronic & \\
\hline Ccng2 & 12452 & 5 & $93,697,763$ & $\mathrm{~T} \rightarrow \mathrm{C}$ & AT to GC transitions & Nonsysnonymous & $\mathrm{I}->\mathrm{T}$ \\
\hline Calcr & 12311 & 6 & $3,650,125$ & $A \rightarrow G$ & AT to GC transitions & Essential splice site & \\
\hline C130060K24Rik & 243407 & 6 & $65,406,380$ & $A \rightarrow G$ & AT to $\mathrm{GC}$ transitions & Nonsysnonymous & $K->E$ \\
\hline Wnk1 & 232341 & 6 & $119,956,300$ & $\mathrm{~A} \rightarrow \mathrm{T}$ & AT to TA transversions & Intronic & \\
\hline Vwf & 22371 & 6 & $125,576,322$ & $\mathrm{G} \rightarrow \mathrm{A}$ & GC to AT transitions & Nonsysnonymous & $M->1$ \\
\hline Klrk1 & 27007 & 6 & $129,566,794$ & $\mathrm{G} \rightarrow \mathrm{A}$ & GC to AT transitions & Intronic & \\
\hline Olfr 1336 & 258917 & 7 & $6,413,462$ & $\mathrm{~A} \rightarrow \mathrm{T}$ & AT to TA transversions & Nonsysnonymous & $\mathrm{T}->\mathrm{S}$ \\
\hline
\end{tabular}


Table 1 List of ENU-induced mutations in G1 mouse of Disc1<Rgsc1390> (Continued)

\begin{tabular}{|c|c|c|c|c|c|c|c|}
\hline NIrp9a & 233001 & 7 & $27,358,923$ & $A \rightarrow C$ & AT to CG transversions & Nonsysnonymous & $\mathrm{E}->\mathrm{A}$ \\
\hline Arhgap33 & 233071 & 7 & $31,315,480$ & $C \rightarrow T$ & GC to AT transitions & Synonymous & \\
\hline \multirow[t]{2}{*}{ Gucy2d } & 14918 & 7 & $105,600,256$ & $A \rightarrow T$ & AT to TA transversions & Exonic & \\
\hline & & 7 & $146,105,909$ & $\mathrm{~T} \rightarrow \mathrm{C}$ & AT to $\mathrm{GC}$ transitions & Intergenic & \\
\hline Rab11fip1 & 75767 & 8 & $28,263,563$ & $G \rightarrow A$ & GC to AT transitions & Nonsysnonymous & $P->L$ \\
\hline$N r 3 c 2$ & 110784 & 8 & $79,741,251$ & $T \rightarrow C$ & AT to $\mathrm{GC}$ transitions & Intronic & \\
\hline Disc1 & 244667 & 8 & $127,611,597$ & $T \rightarrow C$ & AT to GC transitions & Nonsysnonymous & $L->P$ \\
\hline Prdm10 & 382066 & 9 & $31,142,994$ & $T \rightarrow C$ & AT to $\mathrm{GC}$ transitions & Intronic & \\
\hline Olfr909 & 100043200 & 9 & $38,331,305$ & $T \rightarrow C$ & AT to GC transitions & Upstream & \\
\hline Olfr44 & 258716 & 9 & $39,291,849$ & $T \rightarrow G$ & AT to CG transversions & 3' UTR & \\
\hline Pou2f3 & 18988 & 9 & $42,984,368$ & $\mathrm{C} \rightarrow \mathrm{T}$ & GC to AT transitions & Essential splice site & \\
\hline Dyx1c1 & 67685 & 9 & $72,806,667$ & $G \rightarrow A$ & GC to AT transitions & 5' UTR & \\
\hline Unc13c & 208898 & 9 & $73,582,186$ & $T \rightarrow C$ & AT to GC transitions & Intronic & \\
\hline Senp6 & 215351 & 9 & $79,969,034$ & $T \rightarrow G$ & AT to CG transversions & Intronic & \\
\hline Cep63 & 28135 & 9 & $102,521,076$ & $T \rightarrow C$ & AT to GC transitions & Intronic & \\
\hline Heca & 380629 & 10 & $17,635,364$ & $T \rightarrow C$ & AT to GC transitions & Nonsysnonymous & $\mathrm{N}->\mathrm{S}$ \\
\hline Olig3 & 94222 & 10 & $19,077,712$ & $A \rightarrow G$ & AT to $\mathrm{GC}$ transitions & 3' UTR & \\
\hline Sobp & 109205 & 10 & $42,742,835$ & $A \rightarrow T$ & AT to TA transversions & Intronic & \\
\hline Serinc1 & 56442 & 10 & $57,245,307$ & $A \rightarrow G$ & AT to $\mathrm{GC}$ transitions & Intronic & \\
\hline Sf $3 a 2$ & 20222 & 10 & $80,263,982$ & $A \rightarrow G$ & AT to $\mathrm{GC}$ transitions & Nonsysnonymous & $D->G$ \\
\hline Cyp27b1 & 13115 & 10 & $126,485,434$ & $T \rightarrow C$ & AT to $\mathrm{GC}$ transitions & Nonsysnonymous & $V->A$ \\
\hline Tns3 & 319939 & 11 & $8,449,105$ & $\mathrm{~T} \rightarrow \mathrm{A}$ & AT to TA transversions & 5' UTR & \\
\hline 115 & 16191 & 11 & $53,537,612$ & $\mathrm{C} \rightarrow \mathrm{T}$ & GC to AT transitions & 3' UTR & \\
\hline 4930404A10Rik & 74847 & 11 & $54,185,249$ & $\mathrm{~T} \rightarrow \mathrm{A}$ & AT to TA transversions & Nonsysnonymous & $S->R$ \\
\hline Ulk2 & 29869 & 11 & $61,615,130$ & $A \rightarrow T$ & AT to TA transversions & Intronic & \\
\hline S/c13a5 & 237831 & 11 & $72,061,131$ & $\mathrm{C} \rightarrow \mathrm{T}$ & GC to AT transitions & Intronic & \\
\hline$A p 2 b 1$ & 71770 & 11 & $83,183,124$ & $G \rightarrow A$ & GC to AT transitions & Intronic & \\
\hline Lrrc46 & 69297 & 11 & $96,902,597$ & $\mathrm{~T} \rightarrow \mathrm{A}$ & AT to TA transversions & 5' UTR & \\
\hline Erbb2 & 13866 & 11 & $98,297,347$ & $\mathrm{~T} \rightarrow \mathrm{C}$ & AT to GC transitions & Synonymous & \\
\hline Krt40 & 406221 & 11 & $99,401,666$ & $A \rightarrow G$ & AT to $\mathrm{GC}$ transitions & Intronic & \\
\hline Syngr2 & 20973 & 11 & $117,674,256$ & $\mathrm{~T} \rightarrow \mathrm{A}$ & AT to TA transversions & Intronic & \\
\hline Gm9229 & 668539 & 12 & $18,193,251$ & $C \rightarrow A$ & GC to TA transversions & Genic & \\
\hline Mark3 & 17169 & 12 & $112,885,660$ & $\mathrm{~T} \rightarrow \mathrm{C}$ & AT to $\mathrm{GC}$ transitions & Intronic & \\
\hline Igh & 111507 & 12 & $115,853,922$ & $\mathrm{~T} \rightarrow \mathrm{A}$ & AT to TA transversions & Genic & \\
\hline Tcrg-V4 & 21638 & 13 & $19,282,580$ & $A \rightarrow C$ & AT to CG transversions & Genic & \\
\hline Aoah & 27052 & 13 & $21,003,081$ & $A \rightarrow T$ & AT to TA transversions & Intronic & \\
\hline Slc6a3 & 13162 & 13 & $73,682,459$ & $\mathrm{~T} \rightarrow \mathrm{C}$ & AT to $\mathrm{GC}$ transitions & Intronic & \\
\hline Gtf2h2 & 23894 & 13 & $101,240,804$ & $\mathrm{~T} \rightarrow \mathrm{A}$ & AT to TA transversions & Intronic & \\
\hline Ccdc125 & 76041 & 13 & $101,449,272$ & $A \rightarrow G$ & AT to GC transitions & Nonsysnonymous & $D->G$ \\
\hline 3425401B19Rik & 100504518 & 14 & $33,476,075$ & $A \rightarrow G$ & AT to GC transitions & Nonsysnonymous & $1->T$ \\
\hline Mcpt1 & 17224 & 14 & $56,637,381$ & $\mathrm{G} \rightarrow \mathrm{T}$ & GC to TA transversions & Intronic & \\
\hline Atp8a2 & 50769 & 14 & $60,266,756$ & $A \rightarrow G$ & AT to GC transitions & Nonsysnonymous & $\mathrm{Y}->\mathrm{H}$ \\
\hline Sorbs3 & 20410 & 14 & $70,586,596$ & $A \rightarrow T$ & AT to TA transversions & Intronic & \\
\hline Epsti1 & 108670 & 14 & $78,397,889$ & $\mathrm{G} \rightarrow \mathrm{T}$ & GC to TA transversions & Intronic & \\
\hline Diap3 & 56419 & 14 & $87,384,824$ & $G \rightarrow T$ & GC to TA transversions & Intronic & \\
\hline
\end{tabular}


Table 1 List of ENU-induced mutations in G1 mouse of Disc1<Rgsc1390> (Continued)

\begin{tabular}{|c|c|c|c|c|c|c|c|}
\hline Vps13b & 666173 & 15 & $35,570,473$ & $A \rightarrow G$ & AT to GC transitions & Intronic & \\
\hline Ubr5 & 70790 & 15 & $37,898,017$ & $A \rightarrow G$ & AT to GC transitions & 3' UTR & \\
\hline Micall1 & 27008 & 15 & $78,960,399$ & $\mathrm{G} \rightarrow \mathrm{A}$ & GC to AT transitions & Intronic & \\
\hline Cyp2d12 & 380997 & 15 & $82,387,610$ & $A \rightarrow T$ & AT to TA transversions & Intronic & \\
\hline$T t / l 1$ & 319953 & 15 & $83,320,020$ & $\mathrm{G} \rightarrow \mathrm{A}$ & GC to AT transitions & Stop gained & $\mathrm{R}->\mathrm{X}$ \\
\hline Prkag1 & 19082 & 15 & $98,643,692$ & $A \rightarrow G$ & AT to GC transitions & 3' UTR & \\
\hline$G m 7638$ & 665450 & 16 & $11,185,895$ & $C \rightarrow T$ & GC to AT transitions & Genic & \\
\hline Myh11 & 17880 & 16 & $14,269,121$ & $A \rightarrow G$ & AT to GC transitions & Intronic & \\
\hline \multirow[t]{2}{*}{ Gm6931 } & 628903 & 16 & $49,425,860$ & $\mathrm{~T} \rightarrow \mathrm{A}$ & AT to TA transversions & Genic & \\
\hline & & 16 & $80,727,008$ & $A \rightarrow C$ & AT to CG transversions & Intergenic & \\
\hline Olfr125 & 258287 & 17 & $37,972,895$ & $\mathrm{~T} \rightarrow \mathrm{C}$ & AT to GC transitions & Nonsysnonymous & $\mathrm{I}->\mathrm{T}$ \\
\hline Enpp5 & 83965 & 17 & $44,222,094$ & $\mathrm{~T} \rightarrow \mathrm{C}$ & AT to GC transitions & Intronic & \\
\hline Gm7334 & 654432 & 17 & $50,838,499$ & $\mathrm{~T} \rightarrow \mathrm{C}$ & AT to $\mathrm{GC}$ transitions & Genic & \\
\hline Sult1c1 & 20888 & 17 & $54,101,361$ & $\mathrm{~T} \rightarrow \mathrm{C}$ & AT to GC transitions & 3' UTR & \\
\hline $2700099 C 18 R i k$ & 77022 & 17 & $95,163,195$ & $C \rightarrow T$ & GC to AT transitions & Genic & \\
\hline Fhod3 & 225288 & 18 & $25,248,741$ & $A \rightarrow G$ & AT to GC transitions & Nonsysnonymous & $\mathrm{N}->\mathrm{S}$ \\
\hline$K d m 3 b$ & 277250 & 18 & $34,982,966$ & $\mathrm{~T} \rightarrow \mathrm{G}$ & AT to CG transversions & Intronic & \\
\hline Pcdhb6 & 93877 & 18 & $37,493,679$ & $A \rightarrow G$ & AT to GC transitions & Upstream & \\
\hline Pcdhga 1 & 93709 & 18 & $37,912,242$ & $C \rightarrow T$ & GC to AT transitions & Intronic & \\
\hline Spink10 & 328971 & 18 & $62,820,759$ & $\mathrm{G} \rightarrow \mathrm{T}$ & GC to TA transversions & 3' UTR & \\
\hline Cst6 & 73720 & 19 & $5,344,061$ & $A \rightarrow T$ & AT to TA transversions & Intronic & \\
\hline Ganab & 14376 & 19 & $8,987,570$ & $\mathrm{~T} \rightarrow \mathrm{A}$ & AT to TA transversions & Intronic & \\
\hline Cpsf7 & 269061 & 19 & $10,607,448$ & $G \rightarrow T$ & GC to TA transversions & Intronic & \\
\hline Ms4a5 & 269063 & 19 & $11,358,379$ & $\mathrm{~A} \rightarrow \mathrm{T}$ & AT to TA transversions & Upstream & \\
\hline Ms4a14 & 383435 & 19 & $11,382,160$ & $\mathrm{~A} \rightarrow \mathrm{T}$ & AT to TA transversions & Genic & \\
\hline Tjp2 & 21873 & 19 & $24,194,331$ & $\mathrm{~T} \rightarrow \mathrm{C}$ & AT to GC transitions & Intronic & \\
\hline Cyp2c29 & 13095 & 19 & $39,405,010$ & $\mathrm{~T} \rightarrow \mathrm{C}$ & AT to GC transitions & 3' UTR & \\
\hline TII2 & 24087 & 19 & $41,257,593$ & $\mathrm{~T} \rightarrow \mathrm{C}$ & AT to GC transitions & Intronic & \\
\hline Sorcs3 & 66673 & 19 & $48,768,473$ & $A \rightarrow C$ & AT to CG transversions & Nonsysnonymous & $\mathrm{I}->\mathrm{L}$ \\
\hline
\end{tabular}

\section{Discussion}

The present study compared schizophrenia-related behavior among L100P mutant mice (L100P/L100P and $\mathrm{L} 100 \mathrm{P} /+$ ) and their wild-type littermates, and inbred C57BL/6 J mice by testing spontaneous locomotor activity, methamphetamine-induced locomotor activity in the open field [33], and sociability/social novelty preference in the social interaction [34]. All of behavior was comparable among L100P/L100P, L100P/+ and wild-type littermates; the results were partially inconsistent with previous studies using mice originated from the same G1 founder $[24,25]$. To assess effects of genetic background (C57BL/6 J vs DBA/2 J), we conducted comprehensive genotyping of the original G1 mouse and its homozygous offspring obtained by backcrossing to C57BL/6 J, the same strain used for backcrossing in the previous report characterizing the L100P mutant [24]. Our genetic analyses demonstrated that both the L100P/L100P homozygous mice deposited by Roder's group [24] into the EAD at RIKEN and their homozygous progeny still harbored a small number of SNPs inherited from the DBA/2 J strain (the mother of the G1 founder). Whole-exome resequencing of the original G1 genome also revealed an additional 116 single nucleotide variants induced by ENU.

Disc1 L100P was originally identified in one G1 progeny of several thousand screened for Disc1 mutants from a G1 male genomic DNA archive produced by breeding ENU-mutagenized C57BL/6 J males and untreated DBA/2JJcl females [24]. Live heterozygous mice carrying the L100P mutation were recovered by in vitro fertilization of C57BL/6 J eggs with the cryopreserved sperm of the corresponding G1 progeny. In the study reported by Clapcote et al. [24], mutant mice were then backcrossed to the C57BL/6 J background for at least six generations 
before intercrossing $\mathrm{L} 100 \mathrm{P} /+$ mice to generate homozygous mutants for behavioral tests. In theory, the backcrossed congenic mutant strain should have lost most of the other ENU-induced mutations and SNPs derived from DBA/2 J; however, the rate of SNP and mutant loss per generation has not been examined experimentally.

$\mathrm{DBA} / 2 \mathrm{~J}$ and $\mathrm{C} 57 \mathrm{BL} / 6 \mathrm{~J}$ inbred strains were shown to exhibit differential sensitivity to psychostimulants $[35,36]$ without significant differences in basal locomotor activity or sociability [31]. Thus, residual DBA/2 J SNPs, if any still exist in the analyzed mice, could conceivably influence the behavioral test results. Genomic analysis revealed a significant number of DBA/2 J SNPs remaining in the backcrossed Disc1 L100P mice. Among 117 loci tested, nineteen were still polymorphic in the eight L100P/ L100P mice deposited at RIKEN and their progeny (Additional file 2: Table S1). The average frequency of DBA/2 J SNP alleles in the eight L100P/L100P mice was $6.63 \%$ (5.56\%-8.12\%, Additional file 2: Table S1); a rate of genetic vestige was 4.25 -fold higher than the theoretical estimate of $1.56 \%$ [24]. The question arises as to whether any single DBA/2 J SNP or combination influences Disc1 L100P locomotor activity in the open field compared with the congenic background strain. An important feature of the present study was the inclusion of commercially available inbred $\mathrm{C} 57 \mathrm{BL} / 6 \mathrm{~J}$ mice in addition to wild-type littermates derived from Disc1 L100P mutants to assess effects of genetic background on behavioral phenotype. This experimental design could enhance the sensitivity for detecting effects of genetic background and ENU-induced mutations. However, our behavioral analyses showed that neither basal nor methamphetamine-induced locomotor activity differed between wild-type mice derived from Disc1 L100P mutants and inbred C57BL/6 J mice. This finding suggests that locomotor activity is not measurably affected by residual DBA/2 J SNPs. Subsequently, using the exome resequencing analysis, we identified 116 previously unreported mutations in the exome of the original G1 male, although L100P was the only single mutation found in the coding sequence of the Disc1 gene. It has been estimated that approximately $64 \%, 26 \%$ and $10 \%$ of ENU-induced single base pair mutations in coding regions are missense, synonymous, and nonsense mutations, respectively $[28,37,38]$. Intriguingly, the frequencies of base substitutions in the $\mathrm{G} 1$ exome decreased in the rank order of $\mathrm{A} / \mathrm{T}$ to $\mathrm{G} / \mathrm{C}$ transition $>\mathrm{AT} / \mathrm{TA}$ transversion $>\mathrm{G} / \mathrm{C}$ to $\mathrm{A} / \mathrm{T}$ transition $>\mathrm{G} / \mathrm{C}$ to $\mathrm{T} / \mathrm{A}$ transversion $>\mathrm{A} / \mathrm{T}$ to $\mathrm{C} / \mathrm{G}$ transversion, consistent with estimates for the gene-driven approach [39]. Furthermore, the distribution of single base pair mutations in the G1 exome predicted to generate amino acid variants was approximately consistent with previous studies $[37,38]$.

Locomotor activity in the open field did not differ between L100P mutant mice (homozygotes and heterozygotes) and wild-type littermates, consistent with the report by Shoji et al. [27]. In contrast, Clapcote et al. [24] and Lipina et al. [25] reported higher locomotor activity in L100P/L100P mice than in wild-type littermates during the first $30 \mathrm{~min}$, after introduction into the open field (but not thereafter). The higher locomotor activity of L100P mice may represent slower habituation to a novel environment. In addition, although Lipina et al. [25] reported higher locomotor activity in L100P mice following injection of amphetamine compared with that of wild-type littermates, we did not observe enhanced locomotion after an acute challenge with methamphetamine. Although the reasons for this discrepancy with previous reports remains to be explored, one possibility is that critical mutation(s) other than L100P may have been missed during maintenance of the strain after submission to the RIKEN EAD and/or the single backcrossing of homozygous (L100P/ L100P) mutant males obtained from RIKEN to female inbred C57BL/6 J mice. As shown by the distribution of SNPs, the genetic background in the deposited L100P homozygotes was heterozygous; therefore, such heterogeneity may be fixed to either allele in the offspring, even after many generations of maintenance.

The enhanced release of amphetamine-evoked dopamine consistently reported in neuroimaging studies of schizophrenia [40-42] may be of relevance to this model of schizophrenia. However, Lipina et al. [25] did not find greater striatal release of dopamine following amphetamine injection in L100P mice. In the adult brain, Disc1 is expressed in the hippocampus and not in the nucleus accumbens $[43,44]$. The hyperactivity of subcortical dopaminergic neurons is believed to be conveyed by glutamatergic afferents from the hippocampus to the nucleus accumbens, which in turn regulates release of dopamine and the activity of dopaminergic neurons in the ventral tegmental area $[45,46]$. Another possible mechanism relates to disruption of the interaction between the hippocampus and prefrontal cortex [47]. Although subtle cytoarchitectonic changes have been reported in frontal cortical neurons [48], Disc1 L100P mice lack the reduced number of parvalbumin-positive interneurons observed in Disc1 transgenic models [12,18].

Sociability and social novelty preference tests used in the present study are used frequently to investigate disrupted social interactions in mouse models of schizophrenia [34]. The impoverished social interaction in Disc1 mice is believed to be a relevant quantitative trait of social withdrawal in schizophrenia [14]. Consistent with Clapcote et al. [24], we found that the three L100P genotypes did not differ in sociability or social novelty preference. Intriguingly, sociability was markedly impaired in conditional transgenic lines with either constitutive expression of [14] or inducible expression of a mutant DISC1 C-terminal fragment during the early postnatal 
period [15]. We hypothesize that transgenic mice overexpressing human truncated DISC1 protein exhibit a dominant-negative effect that may lead to diminished binding between the DISC1 interacting proteins and relevant domains of DISC1 protein, thus altering the behavioral phenotype [15]. Based on these results, the relevance of Disc1 L100P as a mouse model of schizophrenia should be re-evaluated.

A recent review stressed that ENU-mutagenized mice are useful for establishing novel models of complex human diseases, including neuropsychiatric diseases [49]. A range of ENU-generated mutations based on a phenotype-driven approach has an advantage over a complete loss-of-function mutation in recapturing the pleiotropic nature of human neuropsychiatric diseases and the subtlety of manifestation [49]. Thus, both disease-causative and other unexpected variants should be made publicly available $[28,29]$. This phenotype-driven approach requires high-throughput behavioral screening to link mutation with function. One promising candidate screening methodology is the identification of outliers by neuroimaging. For example, only a few studies on developmental mouse models of psychiatric illness, including those focusing on DN-DISC1 models, have highlighted enlargement of the lateral ventricle without a marked change in overall brain size [16-18,50]. Phenotype screening based on standardized behavioral tests [31,51] combined with neuroimaging [50] to detect enlargement of the lateral ventricle may be an efficacious approach for the identification of robust schizophrenia models.

Several limitations of this study should be considered. First, we did not conduct a mouse comprehensive battery of behavioral tests including cognitive tasks and PPI but only tests of locomotor activity in a novel environment, psychostimulant-induced behavior and sociability in the three-chamber test. Therefore, our results do not clarify effects of the L100P amino acid substitution in exon 2 on other behavioral phenotypes related to psychiatric disorders including schizophrenia. Second, handling, experimental protocols, rearing environment and other environmental factors may influence behavioral test results and contribute to variability across studies [51,52]. Third, L100P mice used in the current study were not genotyped for all ENU-induced mutations found in the exome and vicinity of the G1 genome, some of which may have been transmitted to progeny despite numerous backcrosses [24]. Given that 117 ENU-induced mutations in the G1 mouse identified with the wholeexome resequencing, it is plausible that 50-fold excess or more than 5,000 of ENU-induced mutations should exist in the entire G1 genome. Although detailed genetic information on models relevant to human disease should be freely available, routine implementation of whole-genome sequencing awaits measures for improved cost-effectiveness. However, as most of the ENU-induced mutations in G1 map to chromosomes other than chromosome 8 (containing Disc1), it is likely that they are transmitted to progeny to some extent regardless of the breeding process used to select mice harboring Disc1 100P. Although it may not be possible to investigate whether genetic background or other ENU-induced mutations have any effects on behavior because of a generalised lack of information on genotype differences among any of their mouse lines or offspring, further behavioral and genetic studies are warranted. For example, generation and breeding of another mouse line harboring Disc1 L100P, which can be accomplished by in vitro fertilization by the cryopreserved sperm of the G1 progeny owned by RIKEN BRC, may facilitate full elucidation of a relationship between genetic components, including Disc1 L100P mutation per se, and behavioral phenotypes, related with schizophrenia in this mouse line.

\section{Conclusion}

The present study using behavioral genetic approaches provides an insight into the role of Disc1 L100P and other single nucleotide variants in behavioral phenotypes associated with psychiatric disorders such as schizophrenia. Our present findings suggest that causal attribution of the discrepancy in behavioral phenotypes of the Disc1 L100P mutant mouse line existing among different research groups, including our own, needs to be cautiously investigated in further studies by taking into account the effect(s) of other ENU-induced mutations and/or SNPs from DBA/2 J. Further behavioral genetic analyses are needed to elucidate the cause of behavioral variance associated with Disc1 L100P strain. Using a polygenic animal model including ENU mutagenesis provides an efficacious approach to explore the relationship of variants to behavioral phenotypes associated with polygenic and multifactorial disorders such as psychiatric disorders.

\section{Additional files}

Additional file 1: Figure S1. Pedigree of Disc $1<\operatorname{Rgsc} 1390>$ on RIKEN BRC.

Additional file 2: Table S1. Characteristics of mouse strain SNPs in Disc1<Rgsc1390>.

\section{Competing interests}

Kazufumi Akiyama has received consulting honoraria from Taisho Toyama Pharmaceutical Co., Ltd. This consultancy is totally compliant with the regulation regarding the Conflict of Interest of Dokkyo Medical University School of Medicine, and had no further role in the study design, the collection, analysis and interpretation of data, the writing of the report, or the decision to submit the paper for publication. None of the remaining authors declare any conflicts of interest. 


\section{Authors' contributions}

YA was involved in the design of the study, performed the behaviora experiment, and drafted the manuscript. RF and YG were involved in establishment of the original Disc1 L100P line and discovery of ENU-induced mutations in the exome of the original G1. IM and SW were involved in genotyping of a panel of SNPs in the entire genome of L100P/L100P mice. $\mathrm{KM}$ and $\mathrm{AW}$ were involved in the maintenance of L100P/L100P line that was deposited from the research group (Clapcote et al., 2007 [24]) into the EAD at RIKEN. KA was involved in the editing the manuscript. All authors read and approved final manuscript.

\section{Acknowledgements}

We thank Mikiko Ishikawa for technical assistance. This work was supported by KAKENHI 23890200 and 26860942 from MEXT, Japan. This work was also partly supported by KAKENHI 15200032, 21240043 and 25241016

\section{Author details}

${ }^{1}$ Department of Biological Psychiatry and Neuroscience, Dokkyo Medica University School of Medicine, 800 Kitakobayashi, Mibu-machi, Shimotsuga-gun, Tochigi 321-0293, Japan. ${ }^{2}$ Mutagenesis and Genomics Team, Riken BioResource Center, 3-1-1, Koyadai, Tsukuba-shi, Ibaraki 305-0074, Japan. ${ }^{3}$ Technology and Developmental Team for Mouse Phenotype Analysis, RIKEN BioResourse Center, 3-1-1, Koyadai, Tsukuba-shi, Ibaraki 305-0074, Japan. "Experimental Animal Division, RIKEN BioResourse Center, 3-1-1, Koyadai, Tsukuba-shi, Ibaraki 305-0074, Japan.

Received: 29 August 2014 Accepted: 21 November 2014

Published: 8 December 2014

\section{References}

1. Sullivan PF, Kendler KS, Neale MC: Schizophrenia as a complex trait: evidence from a meta-analysis of twin studies. Arch Gen Psychiatry 2003 60:1187-1192

2. Lichtenstein P, Yip BH, Bjork C, Pawitan Y, Cannon TD, Sullivan PF, Hultman CM: Common genetic determinants of schizophrenia and bipolar disorder in Swedish families: a population-based study. Lancet 2009, 373:234-239.

3. St Clair D, Blackwood D, Muir W, Carothers A, Walker M, Spowart G, Gosden C, Evans HJ: Association within a family of a balanced autosomal translocation with major mental illness. Lancet 1990, 336:13-16.

4. Millar JK, Wilson-Annan JC, Anderson S, Christie S, Taylor MS, Semple CA Devon RS, St Clair DM, Muir WJ, Blackwood DH, Porteous DJ: Disruption of two novel genes by a translocation co-segregating with schizophrenia. Hum Mol Genet 2000, 9:1415-1423.

5. Callicott JH, Straub RE, Pezawas L, Egan MF, Mattay VS, Hariri AR, Verchinski BA, Meyer-Lindenberg A, Balkissoon R, Kolachana B, Goldberg TE, Weinberger DR: Variation in DISC1 affects hippocampal structure and function and increases risk for schizophrenia. Proc Natl Acad Sci U S A 2005, 102:8627-8632.

6. Cannon TD, Hennah W, van Erp TG, Thompson PM, Lonnqvist J, Huttunen M, Gasperoni T, Tuulio-Henriksson A, Pirkola T, Toga AW, Kaprio J, Mazziotta J, Peltonen L: Association of DISC1/TRAX haplotypes with schizophrenia, reduced prefrontal gray matter, and impaired short- and long-term memory. Arch Gen Psychiatry 2005, 62:1205-1213.

7. Hennah W, Tuulio-Henriksson A, Paunio T, Ekelund J, Varilo T, Partonen T, Cannon TD, Lonnqvist J, Peltonen L: A haplotype within the DISC1 gene is associated with visual memory functions in families with a high density of schizophrenia. Mol Psychiatry 2005, 10:1097-1103.

8. Palo OM, Antila M, Silander K, Hennah W, Kilpinen H, Soronen P, Tuulio-Henriksson A, Kieseppa T, Partonen T, Lonnqvist J, Peltonen L, Paunio T: Association of distinct allelic haplotypes of DISC1 with psychotic and bipolar spectrum disorders and with underlying cognitive impairments. Hum Mol Genet 2007, 16:2517-2528.

9. Chubb JE, Bradshaw NJ, Soares DC, Porteous DJ, Millar JK: The DISC locus in psychiatric illness. Mol Psychiatry 2008, 13:36-64.

10. Brandon NJ, Sawa A: Linking neurodevelopmental and synaptic theories of mental illness through DISC1. Nat Rev Neurosci 2011, 12:707-722.

11. Johnstone M, Thomson PA, Hall J, Mclntosh AM, Lawrie SM, Porteous DJ: DISC1 in schizophrenia: genetic mouse models and human genomic imaging. Schizophr Bull 2011, 37:14-20.
12. Hikida T, Jaaro-Peled H, Seshadri S, Oishi K, Hookway C, Kong S, Wu D, Xue R, Andrade M, Tankou S, Mori S, Gallagher M, Ishizuka K, Pletnikov M, Kida S, Sawa A: Dominant-negative DISC1 transgenic mice display schizophrenia-associated phenotypes detected by measures translatable to humans. Proc Natl Acad Sci U S A 2007, 104:14501-14506.

13. Jaaro-Peled $H$, Niwa M, Foss CA, Murai $R$, de Los RS, Kamiya A, Mateo $Y$, O'Donnell P, Cascella NG, Nabeshima T, Guilarte TR, Pomper MG, Sawa A: Subcortical dopaminergic deficits in a DISC1 mutant model: a study in direct reference to human molecular brain imaging. Hum Mol Genet 2013, 22:1574-1580

14. Johnson AW, Jaaro-Peled H, Shahani N, Sedlak TW, Zoubovsky S, Burruss D, Emiliani F, Sawa A, Gallagher M: Cognitive and motivational deficits together with prefrontal oxidative stress in a mouse model for neuropsychiatric illness. Proc Natl Acad Sci U S A 2013, 110:12462-12467.

15. Li W, Zhou Y, Jentsch JD, Brown RA, Tian X, Ehninger D, Hennah W, Peltonen L, Lonnqvist J, Huttunen MO, Kaprio J, Trachtenberg JT, Silva AJ, Cannon TD: Specific developmental disruption of disrupted-in-schizophrenia-1 function results in schizophrenia-related phenotypes in mice. Proc Natl Acad Sci U S A 2007, 104:18280-18285.

16. Pletnikov MV, Ayhan Y, Nikolskaia O, Xu Y, Ovanesov MV, Huang H, Mori S, Moran TH, Ross CA: Inducible expression of mutant human DISC1 in mice is associated with brain and behavioral abnormalities reminiscent of schizophrenia. Mol Psychiatry 2008, 13:173-186. 115.

17. Abazyan B, Nomura J, Kannan G, Ishizuka K, Tamashiro KL, Nucifora F, Pogorelov V, Ladenheim B, Yang C, Krasnova IN, Cadet JL, Pardo C, Mori S, Kamiya A, Vogel MW, Sawa A, Ross CA, Pletnikov MV: Prenatal interaction of mutant DISC1 and immune activation produces adult psychopathology. Biol Psychiatry 2010, 68:1172-1181.

18. Ayhan Y, Abazyan B, Nomura J, Kim R, Ladenheim B, Krasnova IN, Sawa A, Margolis RL, Cadet JL, Mori S, Vogel MW, Ross CA, Pletnikov MV: Differential effects of prenatal and postnatal expressions of mutant human DISC on neurobehavioral phenotypes in transgenic mice: evidence for neurodevelopmental origin of major psychiatric disorders. Mol Psychiatry 2011, 16:293-306.

19. Koike H, Arguello PA, Kvajo M, Karayiorgou M, Gogos JA: Disc1 is mutated in the $12956 / S v E v$ strain and modulates working memory in mice. Proc Natl Acad Sci U S A 2006, 103:3693-3697.

20. Kvajo M, McKellar $H$, Arguello PA, Drew LJ, Moore H, MacDermott AB, Karayiorgou M, Gogos JA: A mutation in mouse Disc1 that models a schizophrenia risk allele leads to specific alterations in neuronal architecture and cognition. Proc Natl Acad Sci U S A 2008, 105:7076-7081.

21. Kvajo M, McKellar H, Drew LJ, Lepagnol-Bestel AM, Xiao L, Levy RJ Blazeski R, Arguello PA, Lacefield CO, Mason CA, Simonneau M, O'Donnell JM, MacDermott AB, Karayiorgou M, Gogos JA: Altered axonal targeting and short-term plasticity in the hippocampus of Disc1 mutant mice. Proc Natl Acad Sci U S A 2011, 108:E1349-E1358.

22. Gondo $Y$ : Now and future of mouse mutagenesis for human disease models. J Genet Genomics 2010, 37:559-572

23. Gondo Y, Fukumura R, Murata T, Makino S: ENU-based gene-driven mutagenesis in the mouse: a next-generation gene-targeting system. Exp Anim 2010, 59:537-548.

24. Clapcote SJ, Lipina TV, Millar JK, Mackie S, Christie S, Ogawa F, Lerch JP, Trimble K, Uchiyama M, Sakuraba Y, Kaneda H, Shiroishi T, Houslay MD, Henkelman RM, Sled JG, Gondo Y, Porteous DJ, Roder JC: Behavioral phenotypes of Disc1 missense mutations in mice. Neuron 2007, 54:387-402.

25. Lipina TV, Niwa M, Jaaro-Peled H, Fletcher PJ, Seeman P, Sawa A, Roder JC Enhanced dopamine function in DISC1-L100P mutant mice: implications for schizophrenia. Genes Brain Behav 2010, 9:777-789.

26. Boulay D, Renard J, Lacave M, Ho-Van S, Lucas MT, Pichat P, Bergis $O_{\text {, }}$ Avenet P, Griebel G: Comparative Behavioral Phenotypical Analysis of Three Transgenic Animal Models Related to Schizophrenia: DISC1 (L100P) Mutant, NMDA NR1 neo-/- Hypomorphic Mice and DAT-/- Mice. In Book Comparative Behavioral Phenotypical Analysis of Three Transgenic Animal Models Related to Schizophrenia: DISC1 (L100P) Mutant, NMDA NR1neo-/Hypomorphic Mice and DAT-/- Mice; 2010. (Editor ed.^eds.). City.

27. Shoji H, Toyama K, Takamiya Y, Wakana S, Gondo Y, Miyakawa T: Comprehensive behavioral analysis of ENU-induced Disc1-Q31L and -L100P mutant mice. BMC Res Notes 2012, 5:108

28. Arnold CN, Barnes MJ, Berger M, Blasius AL, Brandl K, Croker B, Crozat K, Du X, Eidenschenk C, Georgel P, Hoebe K, Huang H, Jiang Z, Krebs P La Vine D, Li X, Lyon S, Moresco EM, Murray AR, Popkin DL, Rutschmann S, 
Siggs OM, Smart NG, Sun L, Tabeta K, Webster V, Tomisato W, Won S, Xia Y, Xiao $N$, et al: ENU-induced phenovariance in mice: inferences from 587 mutations. BMC Res Notes 2012, 5:577.

29. Gunn TM: Functional annotation and ENU. BMC Res Notes 2012, 5:580.

30. Truett GE, Heeger P, Mynatt RL, Truett AA, Walker JA, Warman ML: Preparation of PCR-quality mouse genomic DNA with hot sodium hydroxide and tris (HotSHOT). Biotechniques 2000, 29:52-54.

31. Moy SS, Nadler JJ, Young NB, Perez A, Holloway LP, Barbaro RP, Barbaro JR, Wilson LM, Threadgill DW, Lauder JM, Magnuson TR, Crawley JN: Mouse behavioral tasks relevant to autism: phenotypes of 10 inbred strains. Behav Brain Res 2007, 176:4-20.

32. Ohno M, Sakumi K, Fukumura R, Furuichi M, Iwasaki $Y$, Hokama M, Ikemura T, Tsuzuki T, Gondo Y, Nakabeppu Y: 8-oxoguanine causes spontaneous de novo germline mutations in mice. Sci Rep 2014, 4:4689.

33. van den Buuse M: Modeling the positive symptoms of schizophrenia in genetically modified mice: pharmacology and methodology aspects. Schizophr Bull 2010, 36:246-270.

34. O'Tuathaigh CM, Kirby BP, Moran PM, Waddington JL: Mutant mouse models: genotype-phenotype relationships to negative symptoms in schizophrenia. Schizophr Bull 2010, 36:271-288.

35. Zocchi A, Orsini C, Cabib S, Puglisi-Allegra S: Parallel strain-dependent effect of amphetamine on locomotor activity and dopamine release in the nucleus accumbens: an in vivo study in mice. Neuroscience 1998, 82:521-528.

36. Ventura R, Alcaro A, Cabib S, Conversi D, Mandolesi L, Puglisi-Allegra S: Dopamine in the medial prefrontal cortex controls genotype-dependent effects of amphetamine on mesoaccumbens dopamine release and locomotion. Neuropsychopharmacology 2004, 29:72-80.

37. Takahasi KR, Sakuraba $Y$, Gondo $Y$ : Mutational pattern and frequency of induced nucleotide changes in mouse ENU mutagenesis. BMC Mol Biol 2007, 8:52.

38. Nguyen N, Judd LM, Kalantzis A, Whittle B, Giraud AS, van Driel IR: Random mutagenesis of the mouse genome: a strategy for discovering gene function and the molecular basis of disease. Am J Physiol Gastrointest Liver Physiol 2011, 300:G1-G11.

39. Sakuraba Y, Sezutsu H, Takahasi KR, Tsuchihashi K, Ichikawa R, Fujimoto N, Kaneko S, Nakai Y, Uchiyama M, Goda N, Motoi R, Ikeda A, Karashima Y, Inoue M, Kaneda H, Masuya H, Minowa O, Noguchi H, Toyoda A, Sakaki Y, Wakana S, Noda T, Shiroishi T, Gondo Y: Molecular characterization of ENU mouse mutagenesis and archives. Biochem Biophys Res Commun 2005, 336:609-616.

40. Laruelle M, Abi-Dargham A, van Dyck CH, Gil R, D'Souza CD, Erdos J, McCance E, Rosenblatt W, Fingado C, Zoghbi SS, Baldwin RM, Seibyl JP, Krystal JH, Charney DS, Innis RB: Single photon emission computerized tomography imaging of amphetamine-induced dopamine release in drug-free schizophrenic subjects. Proc Natl Acad Sci U S A 1996, 93:9235-9240.

41. Breier A, Su TP, Saunders R, Carson RE, Kolachana BS, de Bartolomeis A, Weinberger DR, Weisenfeld N, Malhotra AK, Eckelman WC, Pickar D: Schizophrenia is associated with elevated amphetamine-induced synaptic dopamine concentrations: evidence from a novel positron emission tomography method. Proc Natl Acad Sci U S A 1997, 94:2569-2574.

42. Abi-Dargham A, Gil R, Krystal J, Baldwin RM, Seibyl JP, Bowers M, van Dyck CH, Charney DS, Innis RB, Laruelle M: Increased striatal dopamine transmission in schizophrenia: confirmation in a second cohort. Am $J$ Psychiatry 1998, 155:761-767.

43. Miyoshi K, Honda A, Baba K, Taniguchi M, Oono K, Fujita T, Kuroda S, Katayama T, Tohyama M: Disrupted-In-Schizophrenia 1, a candidate gene for schizophrenia, participates in neurite outgrowth. Mol Psychiatry 2003 8:685-694.

44. Austin CP, Ky B, Ma L, Morris JA, Shughrue PJ: Expression of Disrupted-InSchizophrenia-1, a schizophrenia-associated gene, is prominent in the mouse hippocampus throughout brain development. Neuroscience 2004 124:3-10.

45. Legault M, Rompre PP, Wise RA: Chemical stimulation of the ventral hippocampus elevates nucleus accumbens dopamine by activating dopaminergic neurons of the ventral tegmental area. J Neurosci 2000, 20:1635-1642

46. Taepavarapruk P, Floresco SB, Phillips AG: Hyperlocomotion and increased dopamine efflux in the rat nucleus accumbens evoked by electrical stimulation of the ventral subiculum: role of ionotropic glutamate and dopamine D1 receptors. Psychopharmacology 2000, 151:242-251.

47. Peleg-Raibstein D, Pezze MA, Ferger B, Zhang WN, Murphy CA, Feldon J, Bast T: Activation of dopaminergic neurotransmission in the medial prefrontal cortex by $\mathrm{N}$-methyl-d-aspartate stimulation of the ventral hippocampus in rats. Neuroscience 2005, 132:219-232.

48. Lee FH, Fadel MP, Preston-Maher K, Cordes SP, Clapcote SJ, Price DJ, Roder JC, Wong AH: Disc1 point mutations in mice affect development of the cerebral cortex. J Neurosci 2011, 31:3197-3206.

49. Oliver PL, Davies KE: New insights into behaviour using mouse ENU mutagenesis. Hum Mol Genet 2012, 21:R72-R81.

50. Jaaro-Peled H, Ayhan Y, Pletnikov MV, Sawa A: Review of pathological hallmarks of schizophrenia: comparison of genetic models with patients and nongenetic models. Schizophr Bull 2010, 36:301-313.

51. Crawley JN: Behavioral phenotyping strategies for mutant mice. Neuron 2008, 57:809-818.

52. Wahlsten D, Metten P, Phillips TJ, Boehm SL 2nd, Burkhart-Kasch S, Dorow J, Doerksen S, Downing C, Fogarty J, Rodd-Henricks K, Hen R, McKinnon CS, Merrill CM, Nolte C, Schalomon M, Schlumbohm JP, Sibert JR, Wenger CD, Dudek BC, Crabbe JC: Different data from different labs: lessons from studies of gene-environment interaction. J Neurobiol 2003, 54:283-311.

\section{doi:10.1186/1744-9081-10-45}

Cite this article as: Arime et al:: Effects of background mutations and single nucleotide polymorphisms (SNPs) on the Disc1 L100P behavioral phenotype associated with schizophrenia in mice. Behavioral and Brain Functions 2014 10:45.

\section{Submit your next manuscript to BioMed Central and take full advantage of:}

- Convenient online submission

- Thorough peer review

- No space constraints or color figure charges

- Immediate publication on acceptance

- Inclusion in PubMed, CAS, Scopus and Google Scholar

- Research which is freely available for redistribution 